\title{
The impact of a changing financial climate on a UK local charitable sector: voices from the front line
}

\section{Russell Glennon, Claire Hannibal and Joanne Meehan}

\begin{abstract}
Forced to compete with private and public sector providers, charities experience tensions as the quest for a more commercially-oriented position may conflict with their social imperative. Little attention has been given to understanding the experiences of local charities as service providers. This paper captures the reactions of those working on the charity front line.
\end{abstract}

\section{IMPACT}

Austerity is posing significant challenges for charities. This paper suggests that reductions in local government funding and scaling back of council services, along with increasing levels of community demand, are causing pressure within the charitable sector. This is pushing charities towards increased competition, rather than collaboration. Some charities feel excluded from commissioning processes, and that their original social purpose may be under threat.

\section{Keywords: Austerity; change; charities; grid/group theory; social value; VCO.}

Discussion of voluntary and community sector organizations (VCOs) delivering public services is hardly new. Yet in the UK, against the backdrop of rapidly-shrinking budgets and the public services mantra of 'more for less', VCOs, including charities, are being required to develop different forms of accountability for their delivery, as well as different forms of delivery. Changes in government policy initiated after the UK's 2010 general election have begun to have a distinctive effect on the voluntary sector landscape, influencing the roles of markets, hierarchies and networks for public services (Painter, 2011). Rapid shifts in funding as local authorities scale back provision of discretionary services, in some areas directly competing for funds with the voluntary sector, characterize a turbulent funding environment. The effects of this are being experienced in different ways by different parts of the voluntary sector. While research has examined the broader impact of recent policy change on the voluntary and community sector (VCS) overall (Macmillan, 2010), less attention has been given to understanding the experiences of local charitable service providers and their responses to the current funding landscape.

Developing an understanding of the challenges charities face in delivering and evidencing the social contribution they make is essential to understanding the wider context of local selfdetermination and achieving public (financial) value (Moore, 1995). Our paper reports on the experiences of those working on the front line of charitable service provision. Grid/group theory (sometimes referred to as 'cultural theory') (Thompson et al., 1990; Douglas, 1992) is used as a lens to explore the complexity of socio-cultural forces influencing the individual and group action of local charities. In the context of the study grid/group theory (Douglas and Wildavsky, 1983; Wildavsky, 1987: Douglas, 1996), this rovides an explanatory framework for evaluating how individuals and charities view the financial and funding climate, and allows an examination of their consequent behaviours (Loffi et al., 2015). The results of the study contribute to the public administration field by providing a fine-grained analysis of the differing responses of charitable organizations to their funding environment. The sector's response to the move from grants to contracts demonstrates divergence and heterogeneity between charitable organizations as they compete, rather than cooperate, for limited local resources. 


\section{Contextual perspective}

For the past 20 years, charitable and voluntary sector delivery of 'public services' in the UK has been the focus of considerable attention. Macmillan (2010) provides an effective summary of the evidence in this area, concluding that the Labour years governing the UK (1997-2010) saw policies aimed at moving the relationship between the statutory and voluntary sectors from one based around contracts (i.e. as typified by the preceding Conservative administrations) to one based around 'partnership' or joint delivery of desired outcomes. Post-Labour, the UK public policy environment continues to recognize the duty of public authorities to improve the economic, social and environmental wellbeing of society. The recent Public Services (Social Value) Act (2012) requires all public bodies in England and Wales to consider how the services they commission can improve social outcomes in the communities served, while still achieving value for money. The intention behind the Act appears clear - to create and distribute social value - yet there are no specific mechanisms or mandatory requirements for authorities beyond a 'consideration' of applicability, nor an agreed definition of social value (Teasdale et al., 2012). Other acts and government reports collectively articulate a direction of travel and show the policy intention towards devolving responsibility for public service delivery to communities. Along with the Public Services (Social Value) Act, the Localism Act 2011 gives a 'general power of competence' to local authorities. The Open Public Services White Paper (Cabinet Office, 2011) outlines how increased choice, decentralization, accountability and engaging a wider range of providers could make public services more responsive to local needs. The voluntary sector occupies a space in between statutory bodies, private enterprise and civil society (Tracey and Jarvis, 2007), and charities are in a unique position to engage with localism and social value as espoused values.

The emerging political arena forces charitable organizations into competitive markets where they are in direct competition with private and other voluntary sector organizations for revenue. For charities in England and Wales, revenues derived from public expenditure rose from $£ 8$ billion to £12.8 billion between 2000 and 2008 (Clark et al., 2010), yet these figures obscure the tensions and pressures experienced. Core central government budgets have been cut by over $40 \%$, and local council tax has been frozen for several years (LGA, 2015). Central government spending on voluntary sector activity has fallen by $£ 2.3$ billion between 2009/10 and 2013/14; a fall of just over $15 \%$. Public funding of employment and training, culture and recreation, and community development has been subject to the largest cuts

The balance between grants and contracted income has shifted dramatically. In 2002/03, charities received just over half (51\%) their income in grants; by 2012/13, this dropped to just $16.5 \%$ (NCVO, 2015). The move to commercial contract regimes has been accompanied by stricter reporting requirements that add extra pressure to the charitable sector.

Funding is thus triply challenged: central and local government is scaling back spending; nonstatutory funders are more restricted; and there is a widespread move away from grants towards performance-based contracts. These demographic, financial and institutional pressures collectively increase the importance of winning public contracts for charitable organizations to survive. The hybridity of combining financial sustainability and social purpose as a defining characteristic (Doherty et al., 2014) suggests charities would prosper in this new environment. In a free market, however, it is the most efficient organizations that prosper. These tend to be large private sector organizations (Teasdale et al., 2012), particularly in services where there is greater potential for value capture as they can scale operations faster (Santos, 2012). 
Charitable organizations with more focus on value creation than value capture, may be displaced to those services less attractive to commercial organizations, or where market and government failures occur, but which disproportionately affect disadvantaged groups (Santos, 2012). Social organizations cannot be understood in purely economic terms and require contextualization to their local environment and the communities served (Mair and Marti, 2006; Khavul and Bruton, 2013; Dufays and Huybrechts, 2014). It is these local, social environments that create individual priorities and organizational cultures that affect how each charitable organization responds to changes in the environment and political landscape. It is therefore appropriate to adopt a theoretical perspective that permits an examination of the responses to change.

\section{Theoretical perspective}

To provide a theoretical lens to frame our study, we drew upon grid/group and institutional theories as the extent of risk taking-avoidance is linked to cultural biases rooted in particular worldviews or ideologies. These cultural biases represent deeply-held values and patterns of social relations (Wildavsky and Dake, 1990), and have been used previously to examine modes of control of bureaucracy (Hood, 1995) and institutional responses to change that address governance (Stoker, 2003). Grid/group theory provides a four-configuration framework to analyse institutions and cultures and split them into subcultures (see figure 1)

Grid, represented by the $y$ axis, is the extent to which cultures are dominated by rules and regulation (Spickard, 1989; Douglas, 1996). High grid cultures are strongly defined by explicit rules and structures. Risk perceptions can tend toward apathy or ignorance, as the dominant rule culture can insulate people from hazardous activities (Loffi et al., 2015). In low grid cultures, few role distinctions exist and individuals exhibit autonomy - generally these cultures are more individualistic, and behaviours self-regulating. Where competition and autonomy are dominant values in low grid cultures, risk can be viewed as an opportunity for gain (Loffi et al., 2015). Group, represented by the $x$ axis, refers to the pressure to belong to a larger social unit and the extent to which the community controls and regulates membership and participation (Douglas, 1996). High group cultures value solidarity and community. Explicit pressures influence group relationships and collective survival is viewed with higher importance than individual survival (Loffi et al., 2015). Low group cultures are individualist, and value personal entrepreneurialism. There is little emphasis on group-focused commitments, activities, and relationships. Consequently, there can be a short-term approach and organizations/groups can experience high levels of flux (Loffi et al., 2015).

This two-by-two model gives four dominant cultural preference types or subcultures: fatalism, hierarchy, individualism, and egalitarianism (Douglas, 1996). It is important to recognize that these classifications are not goals or targets, but a tool to provide insight into attitudes and behaviours relating to risk.

Grid/group dynamics over time can define organizational cultures (Deal and Kennedy, 2000), and each subculture has a specific set of preferences in how they act, what they value, and how they view the world (Douglas and Wildavsky, 1983; Wildavsky, 1987; Stoker, 2003). The potential for conflict between cultural types is high owing to differences in their inherent values and in how they view the world. We have used grid/group theory to explore how the different cultural biases (Wildavsky and Dake, 1990) of a range of charitable organizations within the same local geographic region respond to the financial changes facing the sector. 
Grid/group therefore represents a mechanism to codify observed changes to organizational and institutional behaviours, values, and attitudes towards risk. We also explore the mechanisms driving such changes to relative positions within the grid/group matrix. Institutional theory suggests that levers for creating change within organizations become institutionalized through implicit and explicit rules, values and behaviours (Hood, 1995). DiMaggio and Powell (1991) suggest that three different types of forces (coercive, normative, and mimetic), will begin to drive organizations to resemble each other through acceptance of a collective rationality. These isomorphic processes affect organizations within a 'field', i.e. similar operating environments, whether this be caused by state, professions or competitive forces. Therefore, our theoretical lens contains two elements: grid/group theory to locate the organizations studied; and institutional theory to explore the mechanisms behind the observed changes.

Figure 1. Grid / group theory, adapted from Douglas (1996).

High Grid: Social relationships are involuntary, and driven by (external) rules

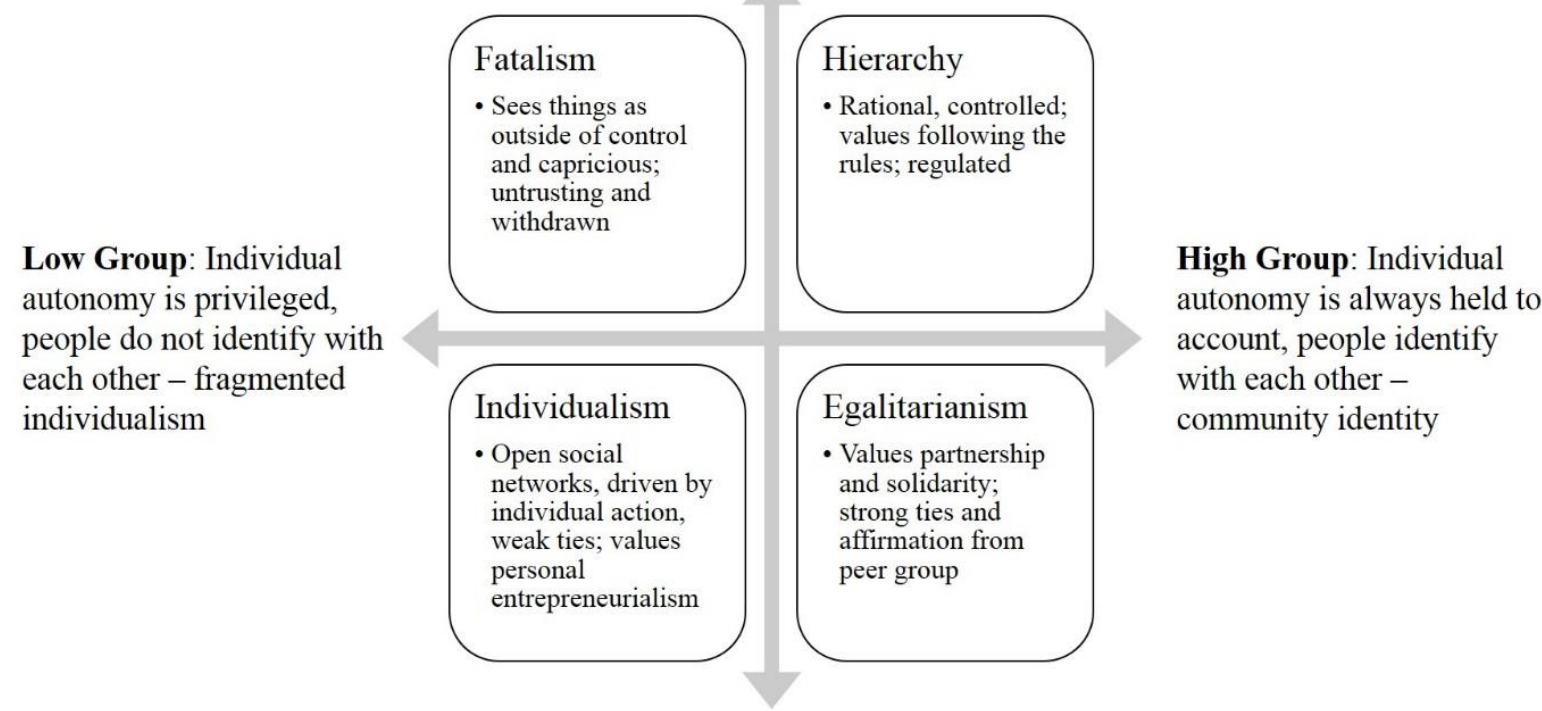

Low Grid: Social relationships are voluntary; people choose to engage (internally driven)

\section{Research design}

The aim of this research is to understand the impact of the changing financial climate on a local charitable sector in the UK by posing the following two questions:

- How are local charitable organizations responding to a changing and challenging funding environment?

- Given the changes in funding, can we observe a divergence from collaborative to more competitive modes of acting?

A voluntary sector infrastructure organization partnered the research and identified potential participants from local charities in the region. Participants were invited through direct emails and via the partner organization's newsletters and social media accounts. Survey methods were deemed inappropriate given the inductive and exploratory research aims. Interviews and focus groups were used to enable participants to guide the research direction. 
Nineteen local charitable organizations agreed to take part in the research. These organizations varied in size, geographical focus and the types of services offered. Two-thirds of these organizations were locally-initiated charities and the remaining third local branches of larger corporate charities. An initial research design anticipated five to seven focus groups and a series of one-to-one interviews with either the founder or the manager of the charitable organization. In practice, representatives of the charities that had agreed to take part in the study were reluctant to be involved in focus groups and only two were able to be scheduled, with one of these having to be cancelled as only one person attended. Six organizations took part in the focus group. Due to the low uptake of involvement in focus groups, we used semi-structured interviews as the principal data collection method. Semi-structured interviews were conducted with the founder or manager of each of the remaining 13 organizations that had not taken part in the focus group. The interviews took place during March to May 2015 and lasted between 30 and 75 minutes. All interviews and the focus group discussion were recorded and transcribed verbatim.

To analyse the data, thematic codes were developed from the transcripts (Miles and Huberman, 1994). Codes were developed individually by each of the three authors, and then reviewed collectively to collapse and combine similarities to ensure a parsimonious coding structure. Each author coded the first two interviews then compared their coding with that of the other authors. Any discrepancies were discussed and resolved and each author then went on to code the remainder of the interviews and the focus group. The key themes emerging from the data were discussed at a meeting with the research partner to strengthen validity. A feedback workshop for all research participants, and other stakeholders, was held in June 2015. Over 20 participants attended including interview/focus group respondents, representatives from the local council and members of other local voluntary sector organizations. The themes presented by the authors resonated with these stakeholders and the workshop served to validate the key findings from the research.

\section{Findings and key themes}

The a priori research questions guided the research design but the data were analysed inductively. Two key nodes emerged from the analysis that are pertinent to the central question of financial and operational sustainability: funding and financial sustainability; and growth, development and maturation.

\section{Funding and financial sustainability}

Unsurprisingly, given the political environment, funding emerged as a key issue. The move from grants towards commissioned funding for direct service provision (Lowndes and Pratchett, 2012; LGA, 2015) has brought about significantly increased expectations from funders for enhanced performance management and financial reporting. While almost all participants accepted that this had brought some managerial and efficiency benefits, there were some significant concerns around the capacity to deliver from the smaller charities: '[Funder reporting requirements are] an absolute nightmare. Weekly reports, monthly reports, get up in the middle of the night reports' (Interview C)

The increasingly short-term nature of funding impeded organizations' ability to plan for the longer term. Many participants commented on how their plans simply included getting to the end of the current contract and applying for further funding. Despite a highly insecure funding environment, some even struggled to contemplate seeking future funding, and a somewhat 
wistful view existed of the security offered by contracts compared to the current volatility and insecurity of external funding: 'some organizations do get funding from them [local authority] every year, we have never had that, as councils have had to move to deliverable services on contracts. Again we have never had the opportunity to bid for the provision of a safe house or housing maintenance or whatever, and get the big contracts...if you get those you are made for that period of time' (Interview E).

Competition is not new to the sector, but emerged as an increasing concern. What was noteworthy here was the changing role of statutory providers, who used to be a source of funding but are now competing against charities to secure external funding. This was seen as a specific threat given their significantly greater capacity for developing bids: 'There has always been a tension as there has always been grant competition, and so I guess it hasn't changed that much, but it has become more prevalent because of huge public sector funding cutbacks...they are our funding sources, and all the local authorities are doing it, or have already done it' (Interview E).

Charities reported a less supportive environment from external funders and a new 'way of doing things'. While learning the 'rules of the game' formed a common motif in narratives surrounding charity development, there was a sense of a material shift in the nature of the funding environment beyond simple competition. This presented itself in two ways - a view that there was a 'clique' or 'inner circle' that had an (unfair) advantage when it came to bidding for contracts; and that the processes for bidding/tendering were themselves opaque and unsupportive and asking for increasingly difficult outcomes: 'I mean with the [name removed] bid it just said: sorry you have been unsuccessful, we had too many applications to give individual feedback so good luck for the future - that is typically what you will get' (Interview G).

Despite many positive stories and experiences, the particular stresses placed on charities and on individuals were evident. Many charities had seen their services diversify and demand grow, particularly in recent months. The reasons for these increases were varied, and included wordof-mouth promotion, the stretching of service boundaries to continue provision as people progress through a journey of needs, and, crucially, the reduction in local authority provision of discretionary services, as well as other funding sources. The scaling back of local authority services may be causing both an increase in demand and a reduction in the capacity within the sector to meet that demand. While no figures were gathered on actual numbers, there was a clear sense from some interviewees of this pressure: 'I think that this is the worst I have seen; I saw it through the $80 \mathrm{~s}$ and this is worse' (Interview C). This view reflected an increasing number of people in need at grassroots level, although it is also worth recognizing that the visible increase in demand only represents those people who feel able to seek help or engage in services. The hidden danger is that others may become increasingly vulnerable if not proactive in seeking out new service providers; this view was also expressed.

\section{Growth, development and maturation}

Participants articulated different phases of organizational development. As organizations grew in terms of scope of services, number of clients/users, and staff/volunteers, there was a need to develop internal infrastructure, governance, and internal policies and processes to sustain the size and breadth reached. This was considered particularly important for winning new commissions or meeting funder going through a state of transition, not in the best way either I would argue, inappropriate people in the roles which was challenging and we had to work through that. So staff, you challenge the culture and the staff do one of three things, leave, stay 
and whinge, or embrace it' (Interview D). Concerns emerged about whether this growth had made a positive or negative contribution to the original mission, vision and values. For example, concerns about becoming too 'corporate' were voiced by many smaller local charities, who felt this moved too far away from the original motivation. In part, this discourse operated as a proxy for the increasingly commercialized, contractual nature of the funding environment. As commissioning begins to drive charities to deliver against the objectives of others, rather than their own, fears surfaced around loss of independence and being changed (presumably for the worse) by funders: 'we aren't just another corporate service which I think a lot of voluntary services have become. So it is about do we have to become that to get funding?' (Interview G.)

The growth in the number of charities represents a dichotomy. On the one hand, a vibrant, growing social sector is to be welcomed; yet, on the other, if this growth represents growing social needs and vulnerability it further underlies deep-rooted issues in communities. The rapid increase in demand for charitable services has created organizational strains. Palpable tensions range from funding and resource limitation, buildings and physical resource constraints, and quandaries regarding the development of a strategic commercial focus to secure sustained revenue, versus using stretched resources to deliver day-to-day services. The general picture across the organizations involved in this study was one of fire-fighting; pressure to adapt to dynamic changes in funding and competition coupled with an inability to plan leading to instability and risk. Funding and revenue remain the lifeblood to secure sustainable service delivery, yet the policy landscape was perceived as preventing the necessary long-term view as organizations move from one short-term tender to another. Many charities in the study noted the need for practical help to navigate the complex environment. Examples including practical support with bid writing, governance structures, financial planning, business planning and forecasting were given, although again, this tended to affect the smaller charities more than the larger ones: 'as an organization I suppose we haven't invested as much in our business development as we have our services' (Interview J).

In addition to the organizational tensions identified, the individuals involved in the sector have experienced some genuine personal strains. Stress, isolation and frustration were common emotions and feelings experienced by the study participants.

\section{Discussion-theoretical interpretations}

While the majority of research participants from smaller charities largely fell more or less into one of the camps of either competitive individualism or community egalitarianism, the policy and funding environment was provoking some potentially significant changes. Some were moving towards fatalism or individualism, and some were becoming more hierarchical (see figure 2). Others had drifted into a fatalistic mode of thinking - a feeling that 'the world is changing, we don't have any control, it's all in the hands of funders and commissioners etc.'. This seemed to be made worse by the weakening of social ties and networks, or 'social capital'. The causal relationship between fatalism and social capital might however work in both directions, or indeed be mutually reinforcing. While it depended on the nature of the project or services offered, there were comments about the loss of networking and support opportunities. This was most often framed as a loss in support from peers, sometimes driven by the overwhelming pressure on finances and resources, or by funder expectations. This was not perhaps a widespread phenomenon, but presents a worrying picture for long-term sustainability, which was the biggest shared concern. It appeared from our research that funder 
expectations (coercive force) were beginning to replace the normative expectations shared between peer organizations as part of bonding social capital.

There was a general sense that weakening ties and significant financial/resource pressures were making organizations introspective by focusing on their own services or interventions, as well as having to deal with increasing demand and fewer resources to meet that demand. This was driving some towards the individualism subculture, and promoting a sense of competition that had previously not been as acute.

Organizations that felt more confident had generally been through a process of developing their governance and structures, often described as 'painful, but necessary'. There was much discussion of the stages of maturity development organizations needed to go through. Few people who established their organization did so because they wanted to run an organization or write a safeguarding policy. Most charities had grown in size and scope, sometimes quite quickly, yet their development had not always matched their growth. The support they needed varied from stage to stage, and almost all of them struggled with developing their own internal organizational structures and systems. Movements from writing grant applications towards writing tenders to win bids evidenced changes in structures and systems, including more sophisticated governance. There was a distinct tension between positive elements of internal systems and the view that this was too 'corporate', signifying a loss of purpose by moving towards 'delivering services', rather than meeting need. The notion of identity and independence was significantly heightened in smaller charities.

Drawing on DiMaggio and Powell, we observed from the interviews that exogenous forces were clearly operating to generate a normative 'professionalization' imperative: 'Yeah, I mean looking back I remember naively not thinking that I wanted anything from... Social Services as they don't know nothing. I wanted to do it all on my own, have the power and all that. But you do need the money, I never wanted to become a charity because I thought you are using your kids to get money, it is how your mind thinks. But it is the best thing that we did as it opens a lot more doors, and a lot of funders want you to become a charity' (Interview B).

Similarity from an institutional sense was largely seen as one of two types: community egalitarianism, i.e. similarity of motives and values, or at least a form of coherence between motives and values; or a form of exclusive, bonding capital that was represented by perceptions of 'cliques' and 'inner-circles':

'Funding is obviously a big thing. People are rightly protective of their own services so people are less likely to give away stuff. Even when you are talking about working in collaboration it feels a bit cliquey. If you are in you hear about it, but if you aren't you don't hear about the new funding streams etc.' (Interview A).

At the same time, for some, the move towards a 'corporate' identity was seen as a diminution of the organization's values and founding principles - a negative, coercive force driven by funder requirements. Larger, corporate charities saw this as a part of a normative operations management approach driven by their 'parent' charity or head office. Smaller charities reported feeling buffeted or pushed into a more 'corporate' mode of delivery that they felt threatened their identity. A choice presented itself: copy the behaviours of the alleged 'clique' of favoured charities (a mimetic force) or reject this imperative, and thus begin to move towards a fatalistic mode of thinking. 
Using the lens of grid/group theory, we observed a shift in type away from the expected mode of community egalitarianism and towards either an individualistic or fatalistic mode for smaller charities, and a strengthening of the hierarchical mode of operation for the larger charities driven largely by a coercive push by funders with regards to expected standards in order to win commissioned service bids. Fracturing intra-organizational support systems have weakened normative forces shaping organizational responses (i.e. what a 'good' charity should do), and a sense began to emerge of a discrete sense of 'preferred' status for some charities, which is naturally covert/ perceived by those who felt themselves outside of the 'clique'.

\section{Conclusions and future research}

This research sought to localize debates about the changes, challenges and questions facing the voluntary sector by exploring a geographically-bounded set of organizations. The results highlight a local charity sector in transition as it adjusts to the direct and indirect consequences of government policy, including the Public Services (Social Value) Act 2012. Despite commonalities among the sector's 'voice' on many of the challenges it faces, the paths chosen in response to the risks vary, and there were some clear differences between locally initiated charities, and local franchises/ operational branches of larger, corporate charities.

Attitudes towards competition, the funding environment and the decreasing levels of local authority funding, coupled with a move towards the commissioning of specific service delivery via contracts, have driven participants into more solitary or hierarchical modes of operation. Many reported a loss of bonding social capital, such as network events, or even sufficient time to have conversations with peers. The local authority continues to exert a strongly normative influence via commissioning, which

is replacing traditional grant regimes, and several participants articulated a sense bitterness around a 'preferred clique' of organizations that were able to best meet the requirements of local authority or other statutory commissioners; these were advanced often by fatalistic participants. Alternative views to this emerged, however, with some evidence of charities being able to proactively offer services and packages to commissioners, rather than simply passively waiting for a tender specification. Opinions were split as to whether commissioners were domineering forces that drove charities in a particular direction, or naïve bodies needing to be told what to do by experienced charitable organizations. Reality, often, lies somewhere between the two poles, and this is an area deserving more attention.

Where relationships with individual commissioners are strong, it is felt to be a more symmetrical relationship. Additional research is required to examine this relationship, and in particular the symmetries and asymmetries of power dynamics between commissioners and 'providers'.

What is also clear is that institutions, such as local authorities, are having a strong influence on the attitudes and behaviours of charities delivering public services. Such influence may not be clear to commissioners, and at a local and national level the rhetoric of social value appears to present opportunities that are simultaneously denied by the harsh funding climate. Some charities are subsequently pulled into areas with increasing demand as discretionary council services diminish, while others move into direct competition for funding not just with private providers, but with local authorities themselves, thus changing the established dynamic of funder and applicant. 


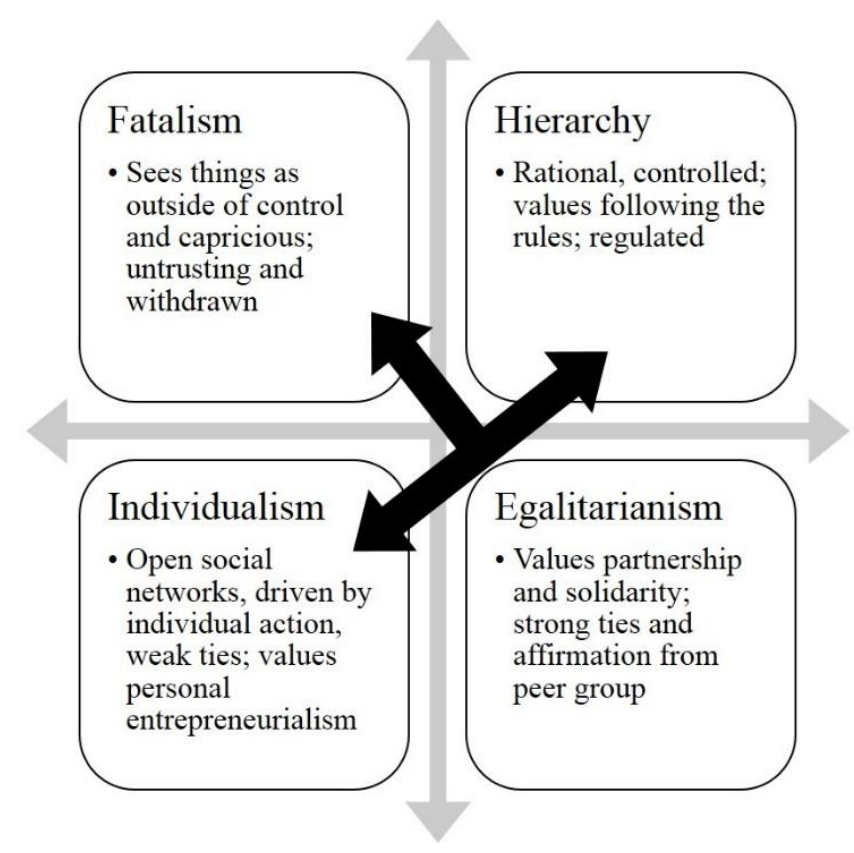

Our paper shines a spotlight on the experiences of local charities in a changing world, but has some limitations. First, data collection was restricted to charities and did not include access to funders, councils or commissioning bodies. Exploring these changing co-option-based relationships, and the impact on operations, is a potentially fruitful area for future research. Second, the scale and geographical reach of our exploratory work is a potential limitation in drawing more general conclusions about the state of the VCS. Nevertheless, as parallels do emerge with the restrictive financial environment of the 1980s driven by Conservative policies (Hood, 1983; Dunsire, 1995), comparative work would make an interesting line of future enquiry. For further work we encourage the adoption of institutional and grid/group theories as they present appropriate lenses through which the impact of public policy decisions on charities can be observed.

\section{References}

Cabinet Office (2011), Open Public Services White Paper, Cm 8145 (The Stationery Office). Clark, J. et al. (2010), The UK Civil Society Almanac 2010 (NCVO).

Deal, T. E. and Kennedy, A. (2000), Corporate Cultures (Jossey-Bass).

DiMaggio, P. J. and Powell, W. W. (1991), The iron cage revisited: institutional isomorphism and collective rationality in organizational fields. The New Institutionalism in Organizational Analysis.

(University of Chicago Press).

Doherty, B., Haugh, H. and Lyon, F. (2014), Social enterprises as hybrid organizations. International

Journal of Management Reviews, 16, 4, pp. 417-436.

Douglas, M. (1992), Risk and Blame: Essays in Cultural Theory (Routledge).

Douglas, M. (1996), Natural Symbols: Explorations in Cosmology (Routledge).

Douglas, M. and Wildavsky, A. (1983), Risk and Culture (University of California Press).

Dufays, F. and Huybrechts, B. (2014), Connecting the dots for social value. Journal of Social Entrepreneurship, 5, 2, pp. 214-237. 
Dunsire, A. (1995), Administrative theory in the 1980s. Public Administration, 73, 1, pp. 1740 .

Hood, C. (1983), The Tools of Government (Macmillan).

Hood, C. (1995), Control over bureaucracy: cultural theory and institutional variety. Journal of Public

Policy, 15, 3, pp. 207-230.

Khavul, S. and Bruton, G. D. (2013), Harnessing innovation for change: sustainability and poverty in developing countries. Journal of Management Studies, 50, 2, pp. 285-306.

LGA (2015), Future Funding Outlook for Councils 2019/20 (LGA).

Loffi, J. M., Wallace, R. J. and Harris, E. L. (2015), An examination of global supply chain security through the lens of grid and group theory. Global Supply Chain Security (Springer).

Lowndes, V. and Pratchett, L. (2012), Local governance under the coalition government: austerity, localism and the 'Big Society'. Local Government Studies, 38, 1, pp. 21-40.

Macmillan, R. (2010), The Third Sector Delivering Public Services (Third Sector Research Centre).

Mair, J. and Marti, I. (2006), Social entrepreneurship research. Journal of World Business, 41, 1, pp. 36-44.

Miles, H. and Huberman, M. (1994), Qualitative Data Analysis (Sage).

Moore, M. H. (1995), Creating Public Value (Harvard University Press).

NCVO (2015), NCVO UK Civil Society Almanac.

Painter, C. (2011), State, markets and society-Big Society joins the fray. Public Money \& Management, 31, 1, pp. 71-74.

Santos, F. M. (2012), A positive theory of social entrepreneurship. Journal of Business Ethics, 111, 3, pp. 335-351.

Spickard, J. V. (1989), A guide to Mary Douglas's three versions of grid/group theory. Sociology of Religion, 50, 2, pp. 151-170.

Stoker, G. (2003), Transforming Local Governance: From Thatcherism to New Labour (Palgrave Macmillan).

Teasdale, S., Alcock, P. and Smith, G. (2012), Legislating for the big society? The case of the Public Services (Social Value) Bill. Public Money \& Management, 32, 3, pp. 201-208.

Thompson, M., Ellis, R. and Wildavsky, A. (1990), Cultural Theory (Westview Press).

Tracey, P. and Jarvis, O. (2007), Toward a theory of social venture franchising. EntrepreneurshipTheory and Practice, 31, 5, pp. 667-685.

Wildavsky, A. (1987), Choosing preferences by constructing institutions: a cultural theory of preference formation. American Political Science Review, 81, 01, pp. 3-21.

Wildavsky, A. and Dake, K. (1990), Theories of risk perception: who fears what and why? Daedalus, 119, 4, pp. 41-60. 